\title{
Effect of Sigma-Phase Morphology on the Properties of Duplex Stainless Steels
}

\author{
M. Poh1*, O. Storz*, T. Glogowski* \\ * Institute for Materials, Ruhr-University Bochum, Universitätsstraße 150, 44780 Bochum, \\ Germany
}

The ferritic-austenitic duplex-steels belong to the group of stainless steels. The compound of the ferritic and austenitic phase is the special advantage of the duplex-steels because it is possible to combine favourable properties of the two crystal systems, resulting in a profile of a high-corrosion resistant construction material, having good mechanical properties. These properties can only be achieved if a precipitation-free structure having a balanced ferrite-/austenite-ratio is available.

The huge amount of alloying elements causes a complex transformation and precipitation behaviour of the duplex-steels. The impact on the mechanical and corrosive properties can to some extent be very substantial. The most critical precipitation, the $\sigma$-phase, forms in a temperature range of $600-$ $1000^{\circ} \mathrm{C}$. Once it has precipitated, it can only be dissolved by annealing above $1050^{\circ} \mathrm{C}$, what again leads to the problem of having just enough cooling rate from high temperatures to avoid a new formation of $\sigma$-phase.

This non-magnetic and intermetallic phase is based on the elements iron and chromium [1], the crystallographic structure is tetragonal. The nucleation of the $\sigma$-phase mainly occurs at the $\alpha / \gamma$ phase-boundaries [2]. The growth of the $\sigma$-phase occurs as a result of a eutectoid transformation of the ferrite into austenite and $\sigma$-phase until the ferrite is completely exhausted. The obtained austenite is considered as tertiary austenite $\left(\gamma_{3}\right)$, which enables a clear separation from other formation mechanisms.

Depending on the isothermal formation temperature, there are different morphologies to be found for the $\sigma$-phase. Lower temperatures lead to a coral-like formation, while higher temperatures (950 ${ }^{\circ} \mathrm{C}$ ) result in a more compact structure (Fig.1).

Figure 2a) shows the tensile-properties subject to the $\sigma$-phase content of different precipitation temperatures. The more cross-linked structures of the 750 and $850^{\circ} \mathrm{C}$ samples show a definite effect on the tensile-strength, whereas an influence of the compact $\sigma$-phase, precipitated at $950^{\circ} \mathrm{C}$, is not identifiable.

The effect of the morphology on the notch bar impact value is represented in Figure 2b). Starting with a very high value of over 300 Joule, the precipitation of one Volume-percent $\sigma$-phase reduces the toughness to a third of the original value. In contrast to the tensile tests, the compact $\sigma$-phase behaves marginal more ductile than the coral morphology.

In addition to the change of mechanical properties, caused by the $\sigma$-phase precipitation, it is to be reckoned that a decrease of the corrosion resistance takes place as well. During the precipitation of the $\sigma$-phase chromium and molybdenum diffuse from the ferritic phase into the $\sigma$-phase. The loss of $\alpha$-stabilizing elements leads to an instable ferrite, transforming into an austenitic-phase $\left(\gamma_{3}\right)$, which is depleted in chromium and molybdenum. Even though the closest packed lattice of the austenite is more resistant to corrosion than the ferritic lattice, the loss of alloying elements prevails, so that the 
tertiary austenite becomes prone to corrosion. The damage manifests itself by a nearly complete dissolution of the network consisting of tertiary austenite.

Summarizing, the ferritic-austenitic duplex-stainless steels have outstanding mechanical and corrosive properties. The necessary high amount of alloying elements causes a complex precipitation and transformation behaviour, which requires professional treatment. Of all precipitations $\sigma$-phase induces the most extensive change in properties. On the one hand the hard and brittle phase causes a reduction of toughness. On the other hand a depleted tertiary austenite $\left(\gamma_{3}\right)$ is formed, which is prone to corrosion.

By isothermal precipitation two different morphologies were found, whose shape depends on the precipitation temperature. An influence of the $\sigma$-phase morphology on the properties was proved.

\section{References}

[1] E.O., Hall, S.H. Algie: Met. Review 11 (1966) 61.

[2] A.J. Strutt, G.W. Lorimer: Conf. Proc., Int. Conf. on Duplex Stainless Steel '86 (1986) 310
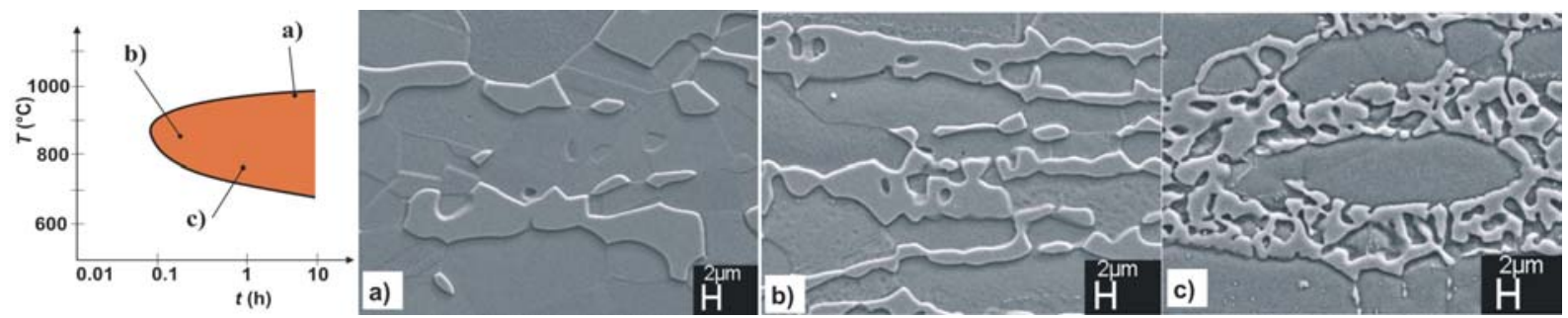

Fig.1. Morphology of the $\sigma$-phase in dependence of the precipitation temperature; a) $750^{\circ} \mathrm{C}, \mathrm{b}$ ) $\left.850^{\circ} \mathrm{C}, \mathrm{c}\right) 950^{\circ} \mathrm{C}$
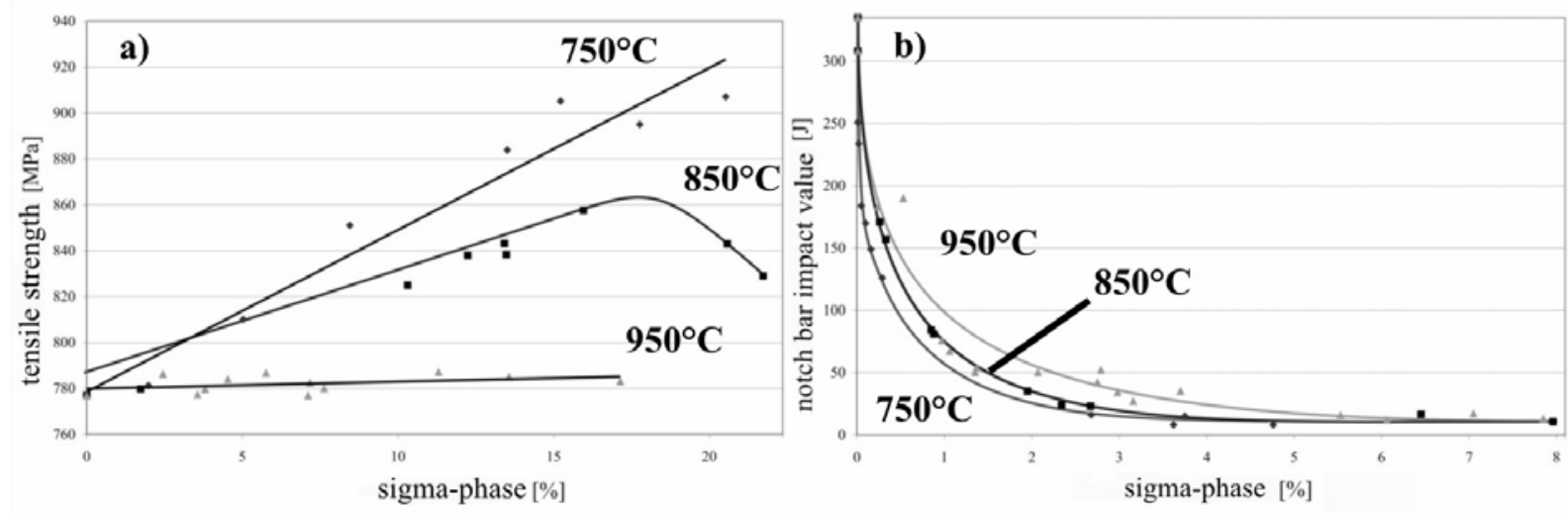

Fig.2. Influence of the precipitation morphology on a) tensile strength and b) notch bar impact value 